\title{
1 Growth rings in tropical trees: Role of functional traits, environment and phylogeny
}

2

3

4 Authors:

5

6 Cheryl D. Nath ${ }^{1}$, François Munoz ${ }^{1,2}$, Raphaël Pélissier ${ }^{3,1}$, David F.R.P. Burslem ${ }^{4}$, G. Muthusankar ${ }^{1}$ 7

$8{ }^{1}$ French Institute of Pondicherry, UMIFRE 21/USR 3330,

9 CNRS-MAEE, 11 St. Louis Street, Pondicherry 605001, India

10

$11{ }^{2}$ Université de Montpellier, UMR AMAP,

12 TA A51/PS2, 34398 Montpellier cedex 5, France

13

$14{ }^{3}$ IRD, UMR AMAP,

15 TA A51/PS2, 34398 Montpellier cedex 5, France

16

$17{ }^{4}$ School of Biological Sciences, University of Aberdeen,

18 Cruickshank Building, St Machar Drive, Aberdeen, AB24 3UU, UK

19

20

21 Corresponding author:

22

23 Cheryl D. Nath

24 Email: cheryl.nath@ifpindia.org

25 Telephone: +91-413-2231624

26 Fax: +91-413-2231605 


\section{Abstract}

28 Most tropical tree species do not produce distinct growth rings and the causes of this phenomenon have not

29 received sufficient quantitative study. It has been shown that rainfall seasonality influences formation of

30 growth rings in some deciduous taxa. However, the numerous exceptions observed call for examination of

31 additional drivers of the phenomenon. We therefore hypothesized that in addition to seasonal climatic

32 stress, functional and phylogenetic constraints may determine growth-ring distinctness. Ten potentially

33 influential factors were examined in 38 Indian tropical tree species. Distinctness of growth rings was

34 quantified based on both subjective visual criteria and objective quantitative measures of anatomical

35 characters. Multivariate and phylogenetically constrained analyses were used to test for functional,

36 environmental and phylogenetic effects.

37 First, subjective scores of growth-ring distinctness correlated with objective anatomical

38 measurements of vessel size and porosity related to water conductance, but also with additional anatomical

39 characteristics unrelated to water dynamics. Second, ring distinctness variables were primarily related to

40 deciduousness and species maximum height, and also weakly influenced by the topographic slope. A

41 phylogenetic signal was detected in wood specific gravity values, the climatic variable of dry-season

42 rainfall and the subjective distinctness score of growth rings, but accounting for phylogenetic structure did

43 not significantly improve the prediction of ring distinctness. Thus, there was no evidence of an evolutionary

44 constraint on the relationship in our sample of species.

45 Our study thus demonstrates how distinctness of growth rings in tropical trees can be objectively

46 represented on a continuous scale, and provides a quantitative explanation for its variability.

\section{$48 \quad$ Keywords}

49 Angiosperm; distinctness of growth rings; deciduousness; drought stress; phylogenetic constraint; South

$50 \quad$ India

\section{Key Message}


53 Subjective and anatomy-based quantitative indices of distinctness of growth rings in tropical trees were

54 related to deciduousness, species maximum height and potentially also to local topography, independent of

55 phylogenetic relationships.

57 Introduction

59 Formation of growth rings is common and well studied in numerous temperate tree species, whereas among

60 tropical angiosperm dicot trees relatively few species are known to produce distinct growth rings (Wheeler

61 et al. 2007). The internationally accepted standard set of "Features for hardwood identification" (IAWA

62 Committee 1989) suggests that tropical species' growth rings can be described as "Distinct", "Indistinct" or

63 "Absent", indicating that growth rings in this part of the world vary widely in terms of visibility and clarity.

64 However, as there are no objective or quantitative standards currently available to define precisely the

65 limits of usage of these terms, there is likely to be much subjectivity in the detection and assignment of

66 growth ring boundaries by different researchers. The obvious question of why all tropical species do not

67 produce distinct growth rings has been studied previously (Détienne 1989; Alves and Angyalossy-Alfonso

68 2000; Callado et al. 2001; Marcati et al. 2006; Lisi et al. 2008), but a fine-scale understanding of the

69 biological mechanisms yielding such observed variations is still lacking and this needs to be acknowledged

70 when classifying tropical tree rings (for example, Carlquist 1988; Worbes 1989) if they vary substantially

71 within species. A better knowledge of the mechanisms underlying formation and distinctness of growth

72 rings is also critical for tropical dendrochronological studies (Stahle 1999; Worbes 2002).

73 Growth rings are likely to be formed when diameter growth reduces substantially or ceases for short

74 intervals of time due to reduction or ending of cambial activity after a growth interval (Alvim 1964;

75 Carlquist 1988; Détienne 1989; Worbes 2002; Lisi et al. 2008; Rozendaal and Zuidema 2011; Mariaux

76 2016). Thus, a first approach to understanding the determinants of distinctness of tree rings across and

77 within species is to identify different circumstances under which growth ceases long enough to cause ring

78 formation in the wood. Formation of growth rings is expected in ecosystems with seasonally varying

79 environments that produce cyclical plant growth (Creber and Chaloner 1984; Stahle 1999). A common

80 proximate mechanism that causes diameter growth to stop is leaf shedding (deciduousness), which could be 
81 triggered by seasonal environmental stress (Alvim 1964; Borchert 1999) and has been clearly linked with

82 dormancy of the cambial meristem in Indian tropical species (Dave and Rao 1982; Rao and Rajput 1999).

83 Crossdating studies have also confirmed that ring formation in some tropical tree species may be related to

84 annual cycles of reduced cambial activity during summer drought (Worbes 1999; Brienen and Zuidema

85 2005), wet season floods (Worbes 1989; Schöngart et al. 2002) and salinity peaks (i.e., in mangrove

86 swamps; Menezes et al. 2003; Verheyden et al. 2004). These events are experienced by plants as either

87 physical or physiological drought, which shuts down diameter growth and induces ring formation (e.g.,

88 floods and salinity may render soils temporarily anoxic, thereby inhibiting root activity and preventing

89 water uptake despite the roots being surrounded by water). From these results we hypothesize that the

90 seasonality and intensity of water shortage (resulting from local climatic and topographic factors) is

91 positively related to formation of distinct rings, and also that tropical deciduous tree species, having

92 evolved to shed leaves in response to water shortage, are more likely to cease growing during the hot dry

93 season and form distinct growth rings compared to evergreen species at the same site. It is possible that the

94 latter also may be vulnerable to reduced cambial activity (or cease cambial activity without shedding

95 leaves) and thus also produce growth rings in the dry season, but this mechanism has not been established

96 clearly in evergreen trees. Consequently, the observation of some evergreen species producing growth rings

97 (Carlquist 1988; Callado et al. 2001; Marcati et al. 2006) has prevented generalization from studies that

98 suggest that leaf shedding is required for growth cessation and ring formation. These observations raise the

99 possibility that endogenous factors (i.e., based on internal rather than external factors, sensu Tomlinson and

100 Longman 1981) may also contribute to formation of growth rings in addition to external environmental

101 stress.

102 The wood economics spectrum (Chave et al. 2009) and earlier theories of life history strategies

103 (Pianka 1970; Grime 1977) suggest several axes of potential covariation among wood traits depending on

104 environmental variation. Yet, a theory of formation of growth rings has not been developed in response to

105 the recognition of this spectrum, and the status of growth rings in a more comprehensive characterization of

106 ecological strategies is still pending. Resource-demanding early successional and fast-growing trees, which

107 are under selection to maximize biomass growth during the favourable growing season (Pianka 1970;

108 Grime 1977), should be expected to possess large vessel size, high porosity of wood (and thus less dense 
109 wood) and large leaves to profit from high resource availability during wood formation early in the growing 110 season (Poorter et al. 2010; Reich 2014). As large vessels are vulnerable to embolism, such species would 111 also be expected to produce smaller vessels under low water availability at the end of the growing season 112 (Baas 1982; Carlquist 1988) and/or shut down growth, perhaps via leaf shedding. In fact, ring porous and 113 semi-ring porous species (cf. IAWA Committee 1989) are known to produce narrow vessels at the end of 114 the growing period that are similar to those of arid region species, indicating that hydraulic safety is more 115 important than water conduction efficiency towards the end of a growing season (Carlquist 1988).

116 Occurrence of co-evolved or coordinated syndromes of traits for fast growth such as large leaves and low 117 wood density (Wright et al. 2006; Chave et al. 2009; Reich 2014) would also make such species more 118 vulnerable to higher evapotranspiration and reduced growth under low soil water and drought conditions 119 compared to conservative and slow-growing species (Ouédraogo et al. 2013), leading to a slowing or 120 cessation of growth during the latter part of a growing season. According to this hypothesis, species with 121 traits adapted for a fast growth strategy thus may be more likely to show greater vessel size variability 122 across a growth ring, ring porosity and formation of distinct growth rings under periodic growth cycles 123 enforced by climatic seasonality.

124 Tree size and growth form are also related to different life history or resource use strategies, which 125 may influence growth cessation and ring formation. For example, in the Brazilian cerrado six tall tree 126 species were observed to produce well-defined and distinct growth rings, and they included both deciduous 127 and evergreen species (Marcati et al. 2006). Studies in tropical evergreen and deciduous forests of India and 128 elsewhere have previously suggested that taller or larger trees may be more vulnerable than smaller trees to 129 the impact of water shortage due to higher exposure and greater demand on stored water (Pélissier and 130 Pascal 2000; Nath et al. 2006; Poorter et al. 2010). We suggest that this is a possible mechanism by which 131 larger trees can be expected to produce more distinct growth rings under drought conditions than smaller 132 trees.

133 Interactions between intrinsic functional traits and environmental factors may also serve to modulate 134 the physiological stress experienced by different species. Further studies are required to address this 135 possibility, as the likelihood of deciduous or tall trees producing distinct rings may be amplified or reduced 136 depending on the local climatic seasonality regime. Previous studies have also hypothesized that climatic 
137 factors such as temperature, photoperiod and precipitation as well as endogenous factors may be 138 responsible for producing growth rings (Tomlinson and Longman 1981; Fahn et al. 1981). In addition,

139 growth ring patterns appear more complex and diverse in tropical than temperate trees, perhaps due to the

140 continuum of different types existing between cyclic and acyclic growth. In this context, a lacuna in

141 tropical wood anatomy studies has been a lack of systematic investigations into variations in formation of

142 growth rings across functional types and environments (Sonsin et al. 2012).

143 In the present work, we addressed the influence of four functional traits on distinctness of growth

144 rings, and hypothesized that their influence is based on species' sensitivity to seasonal drought stress and

145 on their relative position within the fast-slow growth strategy continuum. For ring distinctness assessment,

146 we considered both subjective visual indices of ring distinctness, and quantitative indices of anatomical

147 variation between earlywood and latewood (average vessel area and total porosity ratios, explained below).

148 The functional traits used as predictors of these indices were: 1) leaf phenology (evergreen versus

149 deciduous), as deciduous trees obligatorily cease cambial activity during the dry season (Borchert 1999),

150 ring porosity is strongly associated with deciduousness (Boura and DeFranceschi 2007), and previous

151 studies have suggested that deciduous species are more likely to produce distinct growth rings (Stahle

152 1999; Worbes 1999; Marcati et al. 2006; Nath et al. 2012); 2) species stature (i.e., maximum potential

153 height per species), as tall species tend to be fast growing (King et al. 2006), taller and larger trees have

154 been associated with greater reductions in growth rate during low rainfall years compared to smaller trees

155 (Pélissier and Pascal 2000; Nath et al. 2006) and also appear to be most sensitive to dry season water

156 shortage (Poorter et al. 2010), 3) average leaf length, as longer leaves are associated with species that occur

157 in environments with higher rainfall (McDonald et al. 2003), and larger leaves are associated with faster

158 growth (Wright et al. 2006) and may increase drought vulnerability due to higher evapotranspiration rates

159 than small leaves (Smith 1978; we assume that leaf length, which we measured, is correlated with leaf area

160 as it was not within the scope of this study to obtain values for the latter), and 4) wood specific gravity, as

161 lighter woods are associated with fast growth, larger vessel size and greater vulnerability to cavitation

162 during drought (King et al. 2005; Chave et al. 2009). To our knowledge this is the first study to

163 quantitatively test the influence of multiple functional traits on formation and distinctness of tropical tree

164 rings. 
165 These ecological and functional attributes are the result of evolutionary processes, and a further

166 issue is whether closely related taxa display common inherited patterns of formation of growth rings, or if

167 convergence has occurred among distant lineages under the influence of common selective forces. As

168 evolutionary processes are known to have driven the diversification of anatomical characters among

169 distinct clades (Schweingruber et al. 2007) we might expect the distribution of growth ring types across a

170 phylogeny to reflect the imprint of these processes. It has been suggested that evolutionary relationships

171 may constrain formation of growth rings in tropical trees at the level of genus (Détienne 1989), but there is

172 also evidence of growth ring anatomical variation within genera (Heimsch and Wetmore 1939;

173 Chowdhury1953; Marcati et al. 2006). If growth rings in tropical trees are assumed parsimoniously to be

174 produced by similar physiological mechanisms as in temperate trees, cessation of cambial activity (which

175 results in formation of growth rings) that has evolved as a strategy in temperate trees facing low winter

176 temperatures and frost damage, may be physiologically analogous to similar reduction of cambial activity

177 that has evolved to help tropical trees avoid seasonal drought stress and damage related to embolisms,

178 regardless of taxonomic affiliation. This could potentially lead to evolutionary convergence of growth

179 cessation and ring formation traits across distant clades. In fact, many previous multi-species studies on

180 climatic stress and formation of growth rings in tropical trees have not addressed phylogenetic constraints

181 (Alves and Angyalossy-Alfonso 2000; Lisi et al. 2008; Marcati et al. 2006; Sonsin et al. 2012). It remains

182 to be established whether climatic factors and functional traits are more widely influential than

183 phylogenetic constraints in tropical growth ring development and distinctness, as well as whether there are

184 any phylogenetic constraints on the covariation of growth ring traits and the hypothesized predictors. A

185 better understanding of the respective influences of ecological and evolutionary processes is thus needed,

186 which would benefit or complement palaeobotanical and palaeoclimatological research on past ecosystems.

187 Therefore, our current objective is to address how wood anatomical features associated with formation of

188 growth rings vary across Indian tropical trees, in relation to functional traits, environmental conditions and

189 phylogenetic affinities, making this the first study to examine the joint effects of these factors on tropical

190 tree ring formation.

191 We tested the following main hypotheses, of which the first relates to the development of

192 appropriate methodology and the last two relate to the ecological aspects of the study: 
193 H1: Distinctness of growth rings in tropical tree species can be objectively quantified in terms of

194 measurable anatomical features, which should agree with subjective (visual) assessments.

$195 H 2$ : Intrinsic functional traits that increase a species' drought-sensitivity are associated with distinct growth

196 rings, and are independent of phylogenetic effects. In particular we hypothesized that the traits of

197 deciduousness, species stature, leaf length and the inverse of wood specific gravity would be associated

198 with more distinct rings.

199 H3: The variability and influence of environmental factors (i.e., the topographic variables of elevation,

200 slope and topographic wetness index, as well as the climatic variables of dry season rainfall and potential

201 evapotranspiration) in determining formation of growth rings is independent of phylogenetic effects.

\section{Methods}

206 Study area and data collection

208 The study area was Kodagu district (approximately $11^{\circ} 55^{\prime}-12^{\circ} 49^{\prime} \mathrm{N}$ and $75^{\circ} 22^{\prime}-76^{\circ} 10^{\prime}$ E, Fig. 1) in the

209 Western Ghats of India, a global biodiversity hotspot (Myers et al. 2000). The region is strongly influenced

210 by heavy rainfall annually during the monsoon period (approximately June - October), which alternates

211 with 3-5 months of dry season (i.e., during November - March, when the monthly precipitation is $<100$

$212 \mathrm{~mm})$. The dry season is more intense in the eastern and northern side and is characterized by water

213 shortage, high temperature and high evaporative demand (Pascal 1988). The altitude declines from west to

214 east, with a rainfall gradient from $5000 \mathrm{~mm} \mathrm{yr}^{-1}$ to $800 \mathrm{~mm} \mathrm{yr}^{-1}$ in the same direction (Fig. 1). The

215 landscape is hilly in the west and undulating in the east (Fig. 1), and dominated by traditional coffee

216 plantations in which native trees have been retained to shade the coffee bushes, and these are interspersed

217 with private and government-owned forest fragments. The natural vegetation includes wet evergreen forests

218 on the western side grading into moist or semi-evergreen forest in the central region and dry deciduous

219 forests in the east, with the driest vegetation types in the northeast (Pascal 1988; Elouard 2000). 
221 obtained using a wood punch at a height of approximately $1-1.5 \mathrm{~m}$ on the main trunk of trees. The

222 sampled trees belonged to 38 locally common angiosperm dicot species belonging to 24 families. One to

223 four species were sampled per family (Appendix 1), with one to two trees sampled per species depending

224 on availability (three replicate individuals were used for one species due to high intraspecific variability in

225 the vessel area ratio measure). Eleven families had at least two species sampled, while 13 families had one

226 species sampled. Twenty-nine species had more than one tree (replicate) sampled and a total of 68 trees

227 were used for this study. In species that had more than one replicate sampled, for 23 species the individual

228 trees were sampled from separate sites approximately 5 to $57 \mathrm{~km}$ apart, while six species had two replicates

229 sampled at different locations on the same site (<1 km apart). Thus, replicate trees per species were

230 obtained from an average distance of $12.9 \mathrm{~km}$ apart and for the majority of species the replicates provided

231 intraspecific spatial variability. Sampled trees ranged in girth at breast height ("gbh", circumference

232 measured at $1.3 \mathrm{~m}$ above the ground) from $34 \mathrm{~cm}$ to $348 \mathrm{~cm}$ (average $=130 \mathrm{~cm}$ ) and were in good health.

233 The minimum tree size targeted was $30 \mathrm{~cm}$ girth, as juvenile trees are sometimes less likely to show tree-

234 ring formation (Détienne 1989; Groenendijk et al. 2014; Mariaux 2016). Wood samples were extracted

235 from locations on the stem that were free of knots, buttresses and injuries.

236 Due to legal restrictions over extraction of wood samples from Government-administered forests in

237 Karnataka, our study focused on privately owned shade-coffee plantations (agroforests) or forest patches

238 subject to permission from the landowners, which limited the extent of our sampling design. Most of the

239 wood samples were obtained from 15 traditional multi-species shade-coffee plantations, and eight samples

240 were obtained from two private forest fragments without coffee (i.e., a total of 17 sites, Fig. 1). The

241 plantation sites largely corresponded with those in which previous tree growth studies were carried out

242 (Nath et al. 2011; Nath et al. 2012), and the trees of 38 relatively common species were sought throughout

243 the plantations with the help of local staff. The plantation and forest sites were situated at a distance of 1.1

$244 \mathrm{~km}$ to $57.3 \mathrm{~km}$ apart from each other (Fig. 1).

245 Tree identification was confirmed using field guides, photo documentation, and consultation with

246 botanical experts at the French Institute of Pondicherry. Species nomenclature follows that used by 
247 Mabberley (2005) and the Herbarium of the French Institute of Pondicherry (HIFP,

248 http://www.ifpindia.org/content/herbarium).

250 Measurement of growth ring variables

251

252 Microscope slides were prepared from 68 wood samples by obtaining sections approximately 20 - $30 \mu \mathrm{m}$

253 thick using a GSL-1 sledge microtome and staining with safranin (Gärtner and Schweingruber 2013). Very

254 hard woods were softened by placement of samples under negative pressure using a vacuum pump, (which

255 released trapped air bubbles from within the vessels) and heat $\left(75^{\circ} \mathrm{C}\right.$ water bath) for several days, and in a

256 few extreme cases by soaking for a few days in $\leq 2.5 \%$ sodium hydroxide solution. The resulting

257 microslides were compared against anatomical details available in the published literature and online

258 sources (Gamble 1922; Pearson and Brown 1932; Purkayastha 1999; InsideWood website:

259 insidewood.lib.ncsu.edu/) to confirm similarity of anatomical features and reduce the possibility of

260 obtaining false negative results (i.e., failure to detect rings that had been detected by others). If species were

261 described to have "distinct" or "fairly distinct" growth rings by others but found to have a lower degree of

262 distinctness in our sample, a second replicate collected from a different tree of the same species (if

263 available) was used to prepare a fresh microscope section to confirm the level of distinctness. The

264 anatomical measurements were then averaged across replicates to give a single value per species. Generally

265 our microscopic sections matched or exceeded the level of distinctness of growth rings described in the

266 literature. In Santalum album (only one replicate available) our sample showed no rings whereas it was

267 earlier described as having distinct rings (Gamble 1922) or with the possibility of absent rings at some

268 locations due to intraspecific variation depending on the environmental context (Pearson and Brown 1932).

269 The results were not significantly different if S. album was deleted during analyses, and therefore it was

270 included in the results reported below.

271 Quantitative measures of growth ring occurrence and distinctness were developed, which involved

272 the use of subjective and objective techniques as well as incorporated different biological properties

273 (overall visual assessment versus average vessel size and total porosity). Two subjective variables were

274 developed based on visual characterisation of overall distinctness of growth rings in microscope slides of 
275 wood anatomy, as follows: (i) the overall level of "Visual distinctness" was scored according to the 276 observed clarity of growth rings observed (i.e., distinct $=1$, less distinct $=0.5$, absent $=0$ ); and (ii) several

277 growth ring features were evaluated and combined to create a "Cumulative or composite score"

278 representing overall ring distinctness. For the cumulative score, nine variables were selected based on 279 recommendations from previous studies (IAWA Committee1989; Nath et al. 2012). These features were:

280 1.Porosity type (Ring porous, Semi-ring porous or Diffuse porous)

281 2. Presence of a visible smooth continuous line (i.e., the growth ring boundary line) separating the earlywood (EW) of a new annual growth season from the latewood (LW) of the previous season 3. Vessel size differences between EW and LW across a common growth ring boundary 4. Vessel group size differences between EW and LW (i.e., solitary vs. grouped vessels) 5. Presence of marginal parenchyma at the growth ring boundary (i.e., initial or final parenchyma)

292 visible or rudimentarily formed) or 0 (feature is absent). In the case of Porosity type, ring porous species

293 were assigned a score of 1 , semi-ring porous species were scored as 0.5 and diffuse porous species were

294 scored as 0. From these values a total cumulative score per tree-ring image ("Cumulative distinctness 295 score") was obtained by summing the values across all nine features. A single representative cumulative 296 score was then obtained per species by averaging across the respective replicates.

297 Two objective quantitative measures of distinctness of growth rings were also obtained in terms of 298 average vessel size and total vessel area (i.e., "porosity"), as vessel size and number are among the most 299 reliable environmentally responsive wood traits (Baas 1982; Boura and DeFranceschi 2007; Wheeler et al. 300 2007). We expected these objective continuous measures of distinctness of growth rings to reflect this 301 sensitivity and variability along environmental gradients. Growth rings, when present, were analysed 302 quantitatively using the image analysis software ImageJ (Schneider et al. 2012) to obtain data on average 
303 vessel size and total vessel area in EW and LW on opposite sides of a growth ring boundary line. To obtain 304 quantitative values a rectangular section of the image, having similar dimensions on opposite sides of a

305 growth ring boundary, was extracted from the EW and LW areas, respectively. Whenever possible,

306 attempts were made to randomly select the location of these sample windows across the wood section, but

307 this was restricted to areas with flat and unambiguous growth ring boundaries, sufficient distance between

308 two consecutive ring boundaries for distinguishing earlywood and latewood, and absence of tears or

309 deformities in the anatomical section. The width of the rectangles corresponded approximately to the height

310 of the largest vessel next to the boundary in EW. In general one image was measured per individual tree,

311 but in eight species with growth rings, which had only one replicate individual per species, a second image

312 was obtained from a different location on the microslides produced from the same wood sample. Two

313 objective quantitative variables were then calculated as follows:

314 1. Average vessel area ratio (i.e., average vessel lumen area $\left(\mu \mathrm{m}^{2}\right)$ in EW divided by the corresponding

315 value from the LW section across a common ring boundary). Depending on vessel sizes and the

316 extracted image area, the number of vessels measured per image in EW ranged from 1 to 59 (average $=$

317 8.6) and in LW it ranged from 1 to 35 (average $=9.5$ ).

318 2. Total porosity ratio (i.e., the total lumen area of vessel tissue divided by total observed area, and

319 calculated as a ratio of this value in EW versus in LW)

321 Functional, environmental and phylogenetic predictors

\section{$323 \quad$ Functional trait data}

325 Functional traits of species were collected from various published and online sources and included data on 326 species' leaf phenological strategy (deciduous versus evergreen), species stature (www.biotik.org; Gamble 327 1935; Nazma et al. 1981; Pascal 1988; Murthy and Yoganarasimhan 1990; Rani et al 2011; see Appendix 328 1), and wood specific gravity (Chave et al. 2009; Zanne et al. 2009). Although deciduous species generally 329 increase in frequency as rainfall decreases, we sampled co-occurring deciduous and evergreen species at 330 many sites that spanned a range of rainfall conditions, in order to check for effects of deciduousness that 
331 were independent of the local climatic conditions. Deciduousness was not significantly related to climatic

332 variables in our dataset (Appendix 2). Average leaf length was obtained by measuring five leaves per

333 species from preserved herbarium specimens (HIFP) that were collected at different locations in the

334 Western Ghats. We acknowledge that there may be some underestimation of size due to shrinkage,

335 especially for small-leaved species (Queenborough and Porras 2014), but do not expect it to significantly

336 change the hierarchy of leaf length across species.

Environmental data

340 The geographical coordinates were recorded per coffee plantation or forest fragment during sample

341 collection using a GPS receiver (Trimble Juno SB). In a few cases where GPS data were missing the

342 approximate coordinates were obtained from Google Earth. The corresponding climate and elevation data

343 were downloaded from the WorldClim Global Climate Data website (www.worldclim.org, Hijmans et al.

344 2005) at $1 \mathrm{~km}$ resolution and used to calculate potential evapotranspiration index values per site (PET) from

345 the Thornthwaite and Hargreaves equations, using the R package SPEI (https://cran.r-project.org/). The

346 average PET value for the driest quarter (January to March, assuming that drought stress effects are likely

347 to be most extreme during this period) was calculated per site and used in the analyses. The Bioclim

348 variable \# 17 (total rainfall during the driest quarter, http://www.worldclim.org/bioclim) was also included

349 in our models. As the sites were separated by $>1 \mathrm{~km}$ from all others (Fig. 1) they corresponded to different

350 cells within the Bioclim data-set, at $1 \times 1 \mathrm{~km}$ resolution. As the species were also generally sampled at two

351 sites that were on average $12.9 \mathrm{~km}$ apart, the climatic data averaged across these two replicates provided a

352 unique climatic value per species. In the case of 15 species the climatic data were shared by a few sets of

353 two to five species that happened to be sampled at exactly the same sites.

354 In addition, for each site we calculated the values of mean slope (i.e., topographic incline) and a

355 steady-state wetness index or Topographic Wetness Index (TWI, also known as Compound Topographic

356 Index or CTI, Gessler et al. 1995; Moore et al. 1993). The TWI indicates potential moisture accumulation

357 in relation to the slope and upstream contributing area per unit width orthogonal to the flow direction (i.e., a

358 quantification of catenary topographic convergence) that was calculated as: 


$$
\mathrm{TWI}=\ln (\alpha(\tan \theta))
$$

360 where; $\alpha=$ Catchment area [(flow accumulation +1$) *\left(\right.$ pixel area in $\left.\left.\mathrm{m}^{2}\right)\right]$, and $\Theta=$ slope angle in radians.

361 Catchment area, flow accumulation and slope values were calculated with ArcGIS (www.arcgis.com) from

362 the ASTER Global Digital Elevation Model (NASA LP DAAC 2011).

364 Phylogenetic classification

366 Plant families followed the APG III classification system (The Angiosperm Phylogeny Group 2009). The

367 phylogeny of families was extracted from the phylomatic website (phylodiversity.net/phylomatic/) using 368 the taxize R package (R20120829 version of the family tree), and the species were added at the end of the

369 branches. The resulting phylogeny of species was ultrametric.

Data analysis

373 The dependent variables representing qualitative and quantitative measures of formation of growth rings 374 and distinctness were the following (Table 1):

1. Qualitative (subjective, ordinal) scores: Visual distinctness (scored as $0,0.5$ or 1 )

380 scores, and for possible grouping of species along principal axes of variation, by multivariate ordination of 381 the four variables related to distinctness of growth rings. We used the Hill and Smith (1976) method to 382 accommodate both categorical and quantitative indexes, using the dudi.hillsmith function in the R package, 383 ade4 (Dray and Dufour 2007).

384 We then investigated the influence of the following hypothesized drivers on the dependent variables 385 (Table 1): 
1. Life history and functional traits (species level): leaf phenological type (evergreen/deciduous), species stature, average leaf length and wood specific gravity.

2. Environmental variables (associated with site coordinates): the topographic variables of elevation, slope and topographic wetness index (TWI), and the climatic variables of rainfall during the driest quarter, and the two potential evapotranspiration indices (Thornthwaite and Hargreaves PET

394 First, we tested whether the growth ring features and their hypothesized predictors were more similar 395 among close relatives in the phylogeny (phylogenetic signal, Blomberg and Garland 2002). For this we compared the variance of phylogenetically independent contrasts (PICs) to a null expectation, for all the dependent and independent variables using species’ average values (Blomberg and Garland 2002;

398 Blomberg et al. 2003). The null expectation was obtained by shuffling the tips of the phylogenetic tree (phylosignal function in the R package, picante, Kembel et al. 2010) and randomly resolving the polytomies (i.e., nodes with more than two lineages descended from a single ancestral lineage) into dichotomies within the tree. These results were repeated with 1000 iterations of random selection of individuals from among the available replicates per species. This randomisation test helped assess if

403 significant values obtained by using species average values were robust in the presence of intraspecific 404 variation.

405 We then performed Phylogenetic Generalized Least-Squares regressions (pGLS) to relate each of the 406 three quantitative growth ring variables to the hypothesized functional and environmental predictors $(\mathrm{gls}$

407 function in R package, nlme, Pinheiro et al. 2016), while considering a phylogeny-dependent correlation 408 structure. This correlation structure was based on a Brownian motion model of trait evolution and we 409 performed ANOVA of the models to test the contributions of functional and abiotic predictors, as well as to 410 test the importance of adding phylogenetic information. The full model with ten predictor variables was 411 tested with (pGLS) and without (GLS) phylogenetic structure, and the better model per quantitative growth 412 ring variable was selected based on reduction of the Akaike Information Criterion (AIC) value. This test 413 was also checked for robustness with 10,000 iterations of random selection of a single replicate per species. 
414 Finally, after testing if the phylogenetic structure contributed to the relationship, we expected to 415 retain or remove it from the final model of growth-ring distinctness, when testing the contributions of each

416 predictor. We obtained the most parsimonious model for each of the three quantitative growth ring

417 variables, by starting with an initial full GLS model comprising all the ten independent variables. In some

418 cases the dependent variable was transformed to meet the assumption of normality of residuals, and for two

419 models a single independent variable had to be deleted from the initial full model in order to avoid

420 multicollinearity (details provided in Table 4). To test for multicollinearity, final reduced models were

421 tested for variance inflation factor values (VIF) using the vif function in the R package, car (Fox and

422 Weisberg 2011). A backward stepwise (model reduction) procedure was implemented (using the stepAIC

423 function in the R package, MASS, Venables and Ripley 2002) on this initial model to remove less

424 important predictors, and model selection was based on reduction of the Akaike Information Criterion

425 (AIC) value. Jackknife support for the final parsimonious model was obtained through iterations of the

426 stepwise deletion process (with a different species excluded in every iteration), to establish the robustness

427 of the final parsimonious model using different subsets of species. For the final model that was supported

428 by the highest number of iterations, the jackknife results were used to obtain a confidence range (minimum

429 and maximum, rather than 95\% confidence intervals, due to low sample size) for each estimated coefficient

430 in the model. All analyses were carried out using R, version 3.2.3 (R Development Core Team 2015).

\section{Results}

434 Quantifying distinctness of rings

436 Among the 38 species examined, 11 species were classified as having distinct growth rings (29\%), 21

437 species as having rings with generally variable to low distinctness $(55 \%)$ and the remaining six as having

438 no detectable rings (16\%, Appendix 1). All species with ring porous or semi-ring porous wood (i.e., vessel

439 size, and sometimes also frequency, being many times greater in EW than in LW across a growth ring

440 boundary) had growth rings that were distinct and clearly detectable. In the case of a few diffuse porous

441 woods also, distinct rings could be observed due to the presence of detectable vessel size differences, 
442 extreme fibre density differences or marginal parenchyma rows that clearly marked the growth ring

443 boundary (Fig. 2). The six species with absent rings (scored as zero for visual distinctness and cumulative

444 score) were exclusively evergreen. The proportion of deciduous species increased with increasing visual

445 distinctness of rings, and only one of the 11 species with distinct growth rings was evergreen (Michelia

446 champaca, Magnoliaceae).

447 The two subjective scores of distinctness of growth rings were significantly correlated between

448 themselves (Spearman Rho $(\rho)=0.89, p$-value $<<0.0001$ ), the two objective ratio measures were also

449 significantly correlated between themselves (Spearman $\rho=0.59, p<0.0001$ ), and each of the subjective

450 scores was significantly correlated with the two objective measures (lowest Spearman $\rho=0.42$, all values $p$

$451<0.01)$. This indicates that there was consistency between subjective and objective scores, and the

452 qualitative concept of distinctness of growth rings has a logical basis that can be reliably represented by

453 quantitative methods. Ordination of the four growth ring variables in Hill-Smith analysis captured $88.5 \%$

454 of overall variation with the first two axes. All four growth ring variables were negatively correlated with

455 the first axis (accounting for $73.6 \%$ of total variation), which is indicative of a consistent underlying

456 gradient of ring distinctness in the data. However, the subjective and objective variables were correlated in

457 opposite directions with the second axis (accounting for $15.4 \%$ of total variation) (Fig. 3). This suggests

458 that the two objective variables, vessel size and porosity ratio, may be able to quantify distinctness of

459 growth rings adequately for some species (especially those with ring-porous and semi-ring porous

460 anatomy), but may be inadequate for other species in which the growth ring is characterized by alternative

461 anatomical features such as fiber differentiation, marginal parenchyma, fiber zones, etc. These additional

462 features were incorporated implicitly or explicitly within the subjective scores.

463

464 Phylogenetic effects

465

466 Significant phylogenetic signal was established in only two of the nine explanatory variables tested (wood

467 specific gravity and dry season rainfall), and in one of the quantitative growth ring variables (cumulative

468 distinctness score, Table 2). To test the robustness of these results we reclassified two species, Phyllanthus

469 emblica and Bischofia javanica within the family Phyllanthaceae, in order to align our original 
470 classification with that of The Plant List (http://www.theplantlist.org/). The results were similar when using

471 the new classification and the same two explanatory variables as above had significant phylogenetic signal,

472 but none of the quantitative dependent variables had significant results. The lack of phylogenetic signal in

473 most of the explanatory and independent variables was further supported by an iterative procedure that

474 randomly selected one of the two available replicate values per species and repeated the statistical test 1000

475 times. The randomization procedure produced a significant phylogenetic signal in $100 \%$ of iterations only

476 for wood specific gravity, whereas significant phylogenetic signal was produced in a relatively small

477 proportion of iterations for two additional variables: dry season rainfall (33\%) and cumulative distinctness

478 score (31\%). This indicates that the significant PIC result obtained initially with average species values was

479 not robust in the latter two variables (Table 2; the same result was obtained when tested with the new

480 classification of species). When plotted on the phylogenetic tree to illustrate phylogenetic constraint (Fig.

481 4) almost all of the dependent and independent variables in this study showed no patterning at a deep

482 phylogenetic level. In other words, the traits vary broadly within higher taxa. Therefore the phylogenetic

483 signal, when significant (as in the case of wood specific gravity), may be related to trait conservatism at a

484 finer taxonomic level within families (i.e., more conserved at the genus level).

485 Ordination of the four variables related to distinctness of growth rings together with Hill-Smith

486 analysis at the level of families showed that 11 families, in which more than one species was sampled, had

487 overlapping scores on the first two ordination axes. Such overlaps were inconsistent with the expected

488 relationships observed in a dated family phylogenetic tree (Fig. 5), which is further indicative of a lack of

489 phylogenetic signal. This also suggests that distinctness of growth rings may not be constrained over long

490 evolutionary time frames and possibly is an evolutionarily labile trait.

$491 \quad$ Phylogenetically constrained linear models of distinctness of growth rings, which included all four

492 functional traits and six abiotic predictor variables together, did not show improved fit to the data compared

493 to null models with no phylogenetic correlation structure (AIC of cumulative distinctness score model with

494 phylogenetic structure $=178$, without phylogenetic structure (null) $=171$; AIC of vessel area ratio model

495 with phylogenetic structure $=213$, null $=195$; AIC of porosity ratio model with phylogenetic structure $=$

496176 , null = 165). The lack of improved fit was fully supported by the test with randomized selection of

497 replicates per species using 10,000 iterations for all three dependent variables (these results were confirmed 
498 after reclassifying P. emblica and B. javanica within Phyllanthaceae, according to the Plant List

499 classification of species). This indicates that there was no significant influence of phylogeny, and hence no

500 evolutionary constraint, in the dependence of growth ring variables on their functional and environmental

501 predictors.

502

503 Correlation of explanatory factors with distinctness of growth rings

504

505 As there were no phylogenetic effects we checked for empirical relationships between the explanatory

506 variables and each of the variables related to distinctness of growth rings, using non-parametric correlations

507 (except in the case of the dichotomous variable leaf phenological type, for which a Mann-Whitney U test

508 was used). Among the ten variables tested, leaf phenological type and species stature were significantly

509 correlated with three of the four growth-ring distinctness variables (Table 3).

511 Effects of climate and functional traits

513 Stepwise deletion of less important variables in GLS models without phylogenetic structure resulted in final

514 parsimonious models that retained only one or two important predictors associated with each of the three

515 quantitative growth-ring distinctness variables (Table 4). Each growth ring variable had a different set of

516 predictors, which concurs with the earlier observation that the subjective and objective growth ring indices

517 are partly consistent but also reflect complementary aspects of growth ring patterns (Fig. 3).

518 The growth ring cumulative distinctness score was significantly influenced by leaf phenological type

519 and species stature. Thus, growth rings were generally more distinct in deciduous species and taller trees.

520 Vessel area ratio was influenced significantly by leaf phenological type and non-significantly by slope,

521 whereas porosity ratio was influenced significantly only by leaf phenological type (Table 4). These

522 parsimonious models were supported by $68 \%$ to $92 \%$ of jackknife iterations. The final models obtained for

523 the first two independent variables (cumulative score and vessel area ratio) were tested again with the two

524 retained explanatory variables plus their corresponding interaction term to check for interactive effects

525 using backward stepwise reduction as before, but the interaction term was not retained in both cases. 
526 Leaf phenological type (deciduousness) emerged as the strongest and most consistent predictor that

527 positively influenced all three growth-ring distinctness variables, with significant positive slope values

528 ranging from 0.28 to 1.69 . Species maximum height or stature was significant but weakly associated with

529 the cumulative distinctness score, with a positive slope of 0.06 (Table 4). The non-significant effect of

530 topographic slope on vessel area ratio was weak and negative (-0.03), suggesting that trees on sites with

531 lower slopes had greater growth-ring distinctness. Perhaps this is due to the weak negative correlation

532 between topographic slope and potential evapotranspiration as well as its positive association with dry

533 season rainfall in our study area (Appendix 2, Fig. 1).

\section{Discussion}

538 Objective quantification versus subjective visual classification of distinctness of growth rings

540 Our study has provided a method to complement the conventional qualitative and visual categorization of

541 distinctness of growth rings with quantitative scores and measures reflecting anatomical variation. The

542 results suggest that subjective visual recognition of ring distinctness is the result of cumulative integration

543 of a large number of anatomical features across a growth ring boundary, as demonstrated by the strong

544 relationship between the two subjective scores. The influence of multiple anatomical features was also

545 mentioned by Mariaux (2016). Previous studies have revealed functional plasticity of wood anatomy in

546 some highly responsive species that produce rings with different porosity types according to the external

547 environment (Chowdhury1953; Carlquist 1988). However, the significance of gradation in ring distinctness

548 across species has generally been overlooked in previous studies.

549 The two subjective visual indices provided similar information on distinctness of growth rings across

550 multiple species and ring types. In addition, quantitative support and validation of the subjective scores was

551 provided by the objective measurement of vessel size and porosity ratios across growth ring boundaries,

552 which were calculated by image analysis software and found to be significantly correlated with qualitative

553 indicators of ring distinctness. With these results the subjective concept of "distinctness of growth rings" is 
554 shown to have a logical quantitative basis in well-recognised and measurable growth ring features related to 555 average vessel size and total extent of porosity across a growth ring boundary. Future studies could also

556 examine the opportunity of objective quantification of complementary anatomical features contributing to

557 wood structural heterogeneity, such as differences observed in parenchyma and fibres across growth ring

558 boundaries. Thus, the concept of distinctness of growth rings in tropical trees can be successfully studied

559 using quantitative methods.

560

561 Causes of variation in growth-ring distinctness in tropical trees

562

563 This study provided a plausible and quantitative explanation for why distinctness of growth rings varies

564 widely across tree species in the tropics. The main proximal factors significantly influencing the formation

565 of distinct growth rings in the tropical tree species studied here were leaf phenology (the most common trait

566 that is closely related to seasonal drought effects) and species stature. There was also a weak (non-

567 significant) effect of slope, which may be related to dry season soil moisture stress. The additional

568 functional traits and environmental variables related to topography, rainfall and potential evapotranspiration

569 did not influence distinctness of growth rings in this study. The results also suggest that phylogenetic

570 similarity of distinctness of growth rings may be limited to the fine taxonomic levels (among genera within

571 families), as has been suggested for tree species in tropical Africa and South America (Détienne 1989).

572 Although a robust phylogenetic signal was detected for wood specific gravity, accounting for phylogenetic

573 correlations did not improve our GLS models, and therefore evolutionary constraints did not contribute to

574 explaining the influence of environmental and functional predictors on formation of growth rings and their

575 distinctness.

576 At the interspecific level, distinctness of growth rings may be an evolutionarily labile trait

577 influenced by multiple factors. Chowdhury (1964) suggested that growth ring porosity types may be highly

578 conserved in some families, genera and species but highly variable in others. In this context, we examined

579 descriptions of tree-ring distinctness provided by Pearson and Brown (1932) for 122 species belonging to

58028 families (the family names were assigned based on information available at The Plant List website,

581 http://www.theplantlist.org/, and they include 20 families that were represented in our study). The species' 
582 descriptions were based on microscope slides prepared from at least two replicate samples per species

583 (average $=2.3$ replicates per species, range $=2-8$ replicates) collected from different forest divisions

584 across the Indian subcontinent and stored at the Forest Research Institute, Dehradun, India (Gamble 1922;

585 Pearson and Brown 1932). Among these, eleven families had only one level of growth-ring distinctness

586 each (in these families one to six species were described, averaging 2.3 species described per family), while

587 nine families showed at least two levels of distinctness each (including Meliaceae, with one to 15

588 species/family, averaging 4.2 species described per family) and eight families showed all three levels of

589 distinctness across their species (three to 17 species/family, averaging 7.4 species described per family).

590 This suggests that interspecific variation in tree-ring distinctness within families may increase with the

591 number of species examined (or evolved) per family, which appears to support our finding that tree-ring

592 distinctness is generally labile at the family level. However, there were also a few families exhibiting some

593 level of growth-ring conservatism, wherein only one growth ring type was observed across $\geq 5$ species

594 (e.g., families with numerous species showing distinct rings were: Combretaceae, Verbenaceae, Lauraceae,

595 Fabaceae, Lythraceae and Meliaceae), which supports the prediction of Chowdhury (1964). Increased

596 sampling effort at a lower taxonomic level (i.e., within genera) in the future could allow further assessment

597 of the nature of fine-scale phylogenetic constraint,

598 At the intraspecific level also, distinctness of growth rings may be a labile trait. Intraspecific

599 variation in growth ring distinctness or porosity type has been reported previously in some species (e.g.,

600 Choudhury 1953, 1963, Fichtler and Worbes 2012). The potential for plasticity in growth-ring distinctness,

601 as observed elsewhere, may help explain why conflicting observations of growth ring type and porous

602 nature (i.e., whether ring porous, semi-ring porous or diffuse porous) have been reported for common and

603 widespread species (Chowdhury 1953; Boura et al. 2007). The growth ring descriptions of 122 species

604 (Pearson and Brown 1932) examined by us revealed intraspecific variation of distinctness categories in

$60527 \%$ of the species (this value is $30 \%$ if we consider only the 23 species in which more than two replicate

606 samples were used for preparing microscope slides). This suggests that for a large proportion of Indian

607 species (at least 70\%), the growth ring distinctness category does not vary across different geographic

608 locations. This information also supports our results by indicating that the one or two samples collected by

609 us per species is in fact a meaningful data-set relative to the known variability within species, and as a first 
610 approximation our conclusions are likely to be robust to the assumption that our sampling captures

611 representative species-level values.

612 Ring distinctness is not exclusively based on vessel size and porosity properties alone, but may be

613 related in some species to additional anatomical features that were assessed implicitly or explicitly by the

614 subjective scores. This suggests that distinct ring formation in some tropical south Indian trees may be

615 caused by factors unrelated to water dynamics. For example, low light availability due to heavy cloud cover

616 during the peak monsoon season (July-August) may inhibit growth in species persisting in shade close to

617 the light compensation point for whole-plant growth. In addition, certain phenophases associated with

618 extensive flower or fruit set may inhibit vegetative growth independent of water availability (Callado et al.

619 2001). The signature in growth ring boundaries associated with such causes of growth cessation may be

620 marked by anatomical features other than vessel and porosity variations, such as parenchyma or fiber

621 density variations and marginal parenchyma bands. This also agrees with previous studies suggesting that

622 growth may be stopped and rings produced in wood due to cambial dormancy caused by external abiotic

623 factors (i.e., environment) or internal rhythms (reproductive phenophases, multiannual leaf flushing, etc)

624 that are sometimes referred to as "endogenous factors" (Tomlinson and Longman 1981; Fahn et al. 1981;

625 Callado et al. 2001).

626 This information is useful for tropical dendrochronologists who can in future focus on the functional

627 traits of deciduousness and species stature, to quickly identify locations and tree species that are most likely

628 to produce distinct growth rings (i.e., forests with deciduous and/or tall trees). Our results concur with and

629 complement the strategies suggested by Stahle (1999) for identifying tropical species for

630 dendrochronology. Due to a lack of understanding of formation of growth rings across habitats, taxa and

631 strategies of trees, most tropical dendrochronological studies have been restricted to using a few species

632 with well-established dendrochronological performance records. For example, tropical

633 dendroclimatological studies from India have utilised generally common and widespread species with

634 reliable formation of growth rings and ring-porous to semi-ring porous wood, such as Tectona grandis and

635 Toona ciliata. Only a few other species have been tested for their dendrochronological potential

636 (Bhattacharyya and Shah 2009; Bhattacharyya et al. 2012). Given the high species richness of tropical 
637 forests, there is scope for larger numbers of species to be selected efficiently in the field based on the traits 638 suggested above, for further dendrochronological evaluation and testing in the lab.

640 Functional and evolutionary significance of distinctness of growth rings

642 The hypothesis that formation of distinct growth rings would be associated with a fast growth strategy,

643 characterised by traits such as short-lived leaves that are seasonally shed via deciduousness, was supported

644 by this study. This result allows the phenomenon of distinctness of tropical growth rings to be tentatively

645 located within the hypothesized slow-fast life history continuum that is expected to be characterized by

646 coevolved coordinated traits along plant growth economics spectra (Wright et al. 2006; Chave et al. 2009;

647 Reich 2014). It also suggests a potentially greater sensitivity of fast-growing deciduous species to drought

648 stress (cf. Ouédraogo et al. 2013). However, given the wide variation in leaf phenological types and kinds

649 of adaptation to drought (Borchert 1999; Eckstein 2004; Worbes et al. 2013; Pivovaroff et al. 2015) it

650 would be interesting to examine the relative effects of drought tolerance versus drought avoidance

651 strategies on formation of growth rings. Moreover, a few exceptional deciduous species were observed to

652 produce distinct rings despite being relatively slow growing (Dalbergia latifolia, Terminalia alata and

653 Schleichera oleosa, unpublished data). In these cases perhaps deciduousness and/or tall stature were the key

654 factors influencing ring distinctness, and growth rate was less relevant. The relevance of deciduousness is

655 underlined by its highly significant influence on vessel area ratio. This anatomical feature reflects the

656 porous nature of species (i.e., ring porous or semi-ring porous), which has been previously linked with

657 deciduousness (Boura and De Franceschi 2007). In addition, taller trees have been associated with faster

658 growth rates and/or greater competitive ability (King et al. 2006; Westoby 1998) and species stature was

659 strongly associated with the cumulative growth ring index in our study. Thus, the tall evergreen species,

660 Michelia champaca, produced distinct growth rings without complete leaf shedding. This supports our

661 hypothesis that taller trees may be more likely to show increased distinctness of growth rings, possibly due

662 to drought-related hydraulic constraints and their generally competitive strategy.

663 Leaf length was not a significant predictor of distinctness of growth rings although it was expected

664 to be indirectly associated with a fast growth strategy (through leaf area). This requires further 
665 investigation, preferably with the use of fresh leaves (cf. Queenborough and Porras 2014). Future studies

666 should measure leaf area or specific leaf area, which are considered more conventionally as functional traits

667 that are linked with life history strategies, rather than leaf length (cf. Wright et al. 2006; Reich 2014).

668 Similarly, wood specific gravity was not a significant predictor of growth ring distinctness, perhaps due to

669 unaccounted variability across and within species. For example, some tall trees may belong to long-lived

670 slow-growing species, and wood specific gravity variations may be affected by factors other than fast

671 versus slow growth strategies, such as architecture and soil properties (Iida et al. 2012; Fortunel et al.

672 2014). In addition, wood specific gravity values should be obtained from the field sites if possible, rather

673 than from literature sources, in order to reduce the effects of intraspecific and spatial variability.

674 As distinctness of growth rings was significantly related to the functional traits of leaf phenological

675 strategy and species stature (and potentially also to topographic slope), while the relationship was not

676 influenced by phylogenetic relationships, the evolution of distinctness of growth rings across species does

677 not appear to be evolutionarily constrained. Thus, the rate of change in distinctness of growth rings over

678 time may be independent of general rates of evolution within a clade and may be capable of increasing

679 relatively fast or reversing in response to environmental and endogenous variations. Such information is

680 useful when reconstructing paleoecological conditions including palaeo-climates and the state of functional

681 traits (Baas 1982; Carlquist 1988). A lack of distinctness of growth rings in fossil angiosperm

682 dicotyledonous woods obtained from tropical regions could therefore be interpreted as indicating an

683 evergreen phenological strategy and/or short plant stature. Similarly, a high vessel area ratio across a

684 growth ring boundary (indicating ring porous nature) would suggest a high likelihood of deciduousness.

685 Due to the variability of distinctness of growth rings within families, these traits should not be used to infer

686 phylogenetic relationships above the genus level.

687 If indeed the distinctness of tropical tree growth rings is a relatively labile trait, as suggested by our

688 results, then the proximate cause of distinctness at different locations may vary depending on local

689 environmental conditions and functional trait values. In the Western Ghats, dry season deciduousness

690 appears to be a key factor influencing distinctness of tree rings, and tall trees appear to produce more

691 distinct rings than shorter trees. However, in the case of flooded or mangrove habitats, alternative

692 functional trait variables (for example, absence/presence of pneumatophores and salt excretion 
693 mechanisms) that enhance or diminish the effects of the main seasonal stress factor of soil hypoxia or

694 salinity in those environments (Menezes et al. 2003) may be associated with distinctness of growth rings. It

695 is hoped that our results will stimulate similar quantitative studies on the multiple factors that appear to

696 influence the distinctness of growth rings in tropical and subtropical regions elsewhere.

698 Limitations of our analysis

700 In this paper we described a unique approach towards understanding the relationship between functional or

701 environmental factors and growth ring distinctness in tropical trees. In order to assess the generalisability of 702 these results across other tropical regions the potential limitations of our study are described below, as well

703 as reasons why we expect the conclusions to be robust. We acknowledge that lack of field data on key

704 environmental features such as soil texture and local moisture availability, or individual features such as

705 specific leaf area and wood density may be responsible for the absence of statistical significance in some of

706 the factors tested. Variations in cambial activity that could influence growth ring formation have been

707 previously linked with variations in local climate (Rao and Rajput 1999). However, in our study the

708 variation in dry season rainfall across the sampled sites may have been insufficient to produce marked

709 variations in growth ring formation within species, or alternatively, this may be related to local

710 management practices that partially limit drought effects in the managed coffee plantations. Due to the

711 possibility of intraspecific functional plasticity under different environmental regimes (which may occur in

712 some species), a prospective future approach would be to design more specific sampling of widespread

713 species to address in greater detail the potential for intraspecific variation in growth ring distinctness across

714 habitat types and climatic regimes.

715 We have discussed previously why increased sampling of species per family or individuals per

716 species is unlikely to change our conclusion that there is no general phylogenetic constraint on growth ring

717 formation at the family level. Additional support for our analytical result was provided by randomization

718 tests, use of a modified species classification and secondary information (Pearson and Brown 1932). We

719 thus expect that additional intra-individual variation in ring-distinctness will not modify our results, due to

720 the following reasons: first, this is unlikely to be relevant for species classified as having distinct rings (e.g., 
722 Acrocarpus fraxinifolius and Dalbergia latifolia) as they have been classified similarly by previous studies

723 and successfully crossdated using narrow core samples from arbitrary locations around a stem (Chowdhury

724 1953; Bhattacharyya and Shah 2009; Nath et al. 2012). Second, our sampling and processing methods have

725 minimised the effects of intra-individual variations that may characterise species with less distinct rings.

726 Faint or absent rings have been recorded in juvenile wood near the pith (Détienne 1989; Worbes 2002;

727 Groenendijk et al. 2014; Mariaux 2016), and less commonly species have been reported to show reduced

728 distinctness of growth rings in the outer wood region (Worbes 2002; Groenendijk et al. 2014) or variations

729 in distinctness in the tangential direction (Krepkowski et al. 2012). In addition, detection of rings may be

730 difficult when observing polished wood in the light-coloured sapwood region (Pearson and Brown 1932)

731 due to a lack of contrast under the light microscope. However, we have minimised such limitations by

732 sampling the outer part of stems, selecting trees that were $>30 \mathrm{~cm}$ in girth (i.e., those likely to have

733 completed the juvenile stage), sampling at least two individuals in most species, and using stained

734 microscope slides to detect and characterise the growth rings, thus improving detectability of less distinct

735 rings. Also, among the four different indicators of growth ring distinctness used by us, the two subjective

736 indexes were based on examination of all available rings per microscope slide (sometimes more than five

737 rings per individual). Thus, our subjective characterization of ring distinctness was based on an integrated

738 evaluation of multiple rings per species and may be less sensitive to intra-individual variability. We

739 therefore suggest that future studies could focus on testing different families that were not tested here,

740 including better representation of bioclimatic niches and selecting widespread taxa to enhance the evidence

741 base for testing the hypotheses addressed in this paper.

\section{Author Contribution Statement}

$745 \mathrm{CDN}$ and RP initiated the project; CDN, RP and DFRP planned the initial data collection and analyses;

746 CDN carried out field and lab work; CDN, FM and GM carried out analyses; all authors contributed to 747 manuscript preparation. 


\section{$750 \quad$ Acknowledgments}

751

752 Financial support of the Centre National de la Recherche Scientifique (USR 3330), France, and from the

753 Rufford Small Grants Foundation (UK) is acknowledged. We thank the private farmers and coffee

754 plantation companies of Kodagu for providing permissions and logistical support for this project. We are

755 grateful to N. Barathan for assistance with slide preparation and data entry, S. Aravajy for botanical

756 assistance, S. Prasad and G. Orukaimoni for technical inputs, and A. Prathap, S. Shiva, B. Saravana and P.

757 Shiva for field assistance. The corresponding editor and three anonymous reviewers provided insightful

758 comments that improved the manuscript.

759

760

\section{$761 \quad$ Conflict of interest}

762

763 The authors declare that they have no conflict of interest. 


\section{References}

Alves ES, Angyalossy-Alfonso V (2000) Ecological trends in the wood anatomy of some Brazilian species. 1. Growth rings and vessels. IAWA J 21:3-30

Alvim P deT (1964) Tree growth periodicity in tropical climates. In: Zimmerman MH (ed) The formation of wood in forest trees. Academic Press, New York, pp 479-495

Baas P (1982) Systematic, phylogenetic, and ecological wood anatomy - History and perspectives. In: Baas P (ed) New perspectives in wood anatomy. Martinus Nijhoff/Dr W Junk Publishers, The Hague, pp 23-58

Bhattacharyya AA, Shah SK (2009) Climatic Tree-ring studies in India: Past appraisal, present status and future prospects. IAWA J 30:361-370

Bhattacharyya A, Shekhar M, Shah SK (2012) Role of Tree-ring study in forest management: Prospects in Indian context. In: Panda S and Ghosh C (eds) Diversity and conservation of plants and traditional knowledge. Bishen Singh Mahendra Pal Singh, Dehra Dun, pp 287-298

Blomberg SP, Garland T, Ives AR (2003) Testing for phylogenetic signal in comparative data: Behavioral traits are more labile. Evolution 57:717-745

Blomberg SP, Garland T (2002) Tempo and mode in evolution: phylogenetic inertia, adaptation and comparative methods. J Evol Biol $15: 899-910$

Borchert R (1999) Climatic periodicity, phenology, and cambium activity in tropical dry forest trees. IAWA J 20:239-247

Boura A, de Franceschi D (2007) Is porous wood structure exclusive of deciduous trees? CR Palevol $6: 385-391$

Brienen RJW, Zuidema PA (2005) Relating tree growth to rainfall in Bolivian rain forests: a test for six species using tree ring analysis. Oecologia 146:1-12

Callado CH, Neto SJS, Scarano FR, Costa CG (2001) Periodicity of growth rings in some flood-prone trees of the Atlantic Rain Forest in Rio de Janeiro, Brazil. Trees 15:492-497

Carlquist S (1988) Comparative wood anatomy: Systematic, ecological and evolutionary aspects of dicotyledon wood. Springer-Verlag, Berlin

Chave J, Coomes D, Jansen S, et al. (2009) Towards a worldwide wood economics spectrum. Ecol Letters 12:351-366

Chowdhury KA (1953) The role of initial parenchyma in the transformation of the structure diffuse-porous to ring-porous in the secondary xylem of the genus Gmelina Linn. Proc Nat Inst Sci India 19:361-369

Chowdhury KA (1964) Growth rings in tropical trees and taxonomy. J Ind Bot Soc 43: 334-342

Creber GT, Chaloner WG (1984) Influence of environmental factors on the wood structure of living and fossil trees. Bot Rev 50:357-448

Dave YS, Rao KS (1982) Seasonal activity of the vascular cambium in Gmelina arborea Roxb. IAWA Bull ns 3:59-65

Détienne P (1989) Appearance and periodicity of growth rings in some tropical woods. IAWA Bull ns 10:123-132 
Dray S, Dufour AB (2007) The ade4 Package: Implementing the Duality Diagram for Ecologists. J. Stat.

Elouard C (2000) Vegetation features in relation to biogeography. In: Ramakrishnan PS, Chandrashekara UM, Elouard C et al. (eds) Mountain biodiversity, land use dynamics, and traditional ecological knowledge. Oxford/IBH, New Delhi, pp25-42

Fahn A, Burley J, Longman KA, Mariaux A (1981) Possible contributions of wood anatomy to the determination of the age of tropical trees. In: Bormann FH, Berlyn G (eds) Age and growth rate of tropical trees: New dimensions for research. Yale University, New Haven, pp 31-54

Fichtler E, Worbes M (2012) Wood anatomical variables in tropical trees and their relation to site conditions and individual tree morphology. IAWA J 33:119-140

Fortunel C, Ruelle J, Beauchêne J, et al. (2014) Wood specific gravity and anatomy of branches and roots in 113 Amazonian rainforest tree species across environmental gradients. New Phytol 202:79-94

Fox J, Weisberg S (2011) An R Companion to Applied Regression, Second Edition. Sage, Thousand Oaks, CA.

Gamble JS (1922) A manual of Indian timbers. Sampson Low, Marston and Co, London

Gamble JS (1935) Flora of the Presidency of Madras. Adlard, London

Gärtner H, Schweingruber FH (2013) Microscopic preparation techniques for plant stem analysis. Kessel Publishing House, Remagen

Gessler PE, Moore ID, McKenzie NJ, Ryan PJ (1995) Soil-landscape modeling and spatial prediction of soil attributes. Int J GIS. 9:421-432

Grime JP (1977) Evidence for the existence of three primary strategies in plants and its relevance to ecological and evolutionary theory. Am Nat 111:1169-1194

Groenendijk P, Sass-Klaassen U, Bongers F, Zuidema PA (2014) Potential of tree-ring analysis in a wet tropical forest: A case study on 22 commercial tree species in Central Africa. For Ecol Manage 323:65-78

Heimsch C, Wetmore RH (1939) The significance of wood anatomy in the taxonomy of the Juglandaceae. Am J Bot 26:651-660

Hijmans RJ, Cameron SE, Parra JL, et al. (2005) Very high resolution interpolated climate surfaces for global land areas. Int J Climatol 25:1965-1978

Hill MO, Smith AJE (1976) Principal component analysis of taxonomic data with multi-state discrete characters. Taxon 25:249-255

IAWA Committee (1989) IAWA List of microscopic features for hardwood identification. IAWA Bull. n.s. 10:219-332

Iida Y, Poorter L, Sterck FJ, et al. (2012) Wood density explains architectural differentiation across 145 cooccurring tropical tree species. Funct Ecol 26:274-282

Kembel SW, Cowan PD, Helmus MR, et al. (2010) Picante: R tools for integrating phylogenies and ecology. Bioinf 26:1463-1464 
King DA, Davies SJ, Nur Supardi MN, Tan S (2005) Tree growth is related to light interception and wood density in two mixed Dipterocarp forests of Malaysia. Funct Ecol 19:445-453

King DA, Davies SJ, Noor NSM (2006) Growth and mortality are related to adult tree size in a Malaysian mixed dipterocarp forest. For Ecol Manage 223:152-158

Krepkowski J, Bräuning A, Gebrekirstos A (2012) Growth dynamics and potential for cross-dating and multi-century climate reconstruction of Podocarpus falcatus in Ethiopia. Dendrochronologia 30:257-265

Lisi CS, Tomazello FM, Botosso PC, et al. (2008) Tree-ring formation, radial increment periodicity, and phenology of tree species from a seasonal semi-deciduous forest in southeast Brazil. IAWA J 29:189-207

Mabberley DJ (2005) The plant-book: A portable dictionary of the vascular plants. Cambridge University Press, Cambridge

Marcati CR, Oliveira JS, Machado SR (2006) Growth rings in cerrado woody species: Occurrence and anatomical markers. Biota Neotropica v6 (n3) -

http://www.biotaneotropica.org.br/v6n3/pt/abstract?article+bn00206032006 Accessed 6 August 2015

Mariaux A (2016) Nature and periodicity of growth rings in African timber: Can they be used to determine the age of trees? (I. Bossanyi, Trans.) Bois et Forêts des Tropiques 327:51-76

McDonald PG, Fonseca CR, Overton JMCC, Westoby M (2003) Leaf-size divergence along rainfall and soil-nutrient gradients: is the method of size reduction common among clades? Funct. Ecol. 17:50-57

Menezes M, Berger U, Worbes M (2003) Annual growth rings and long-term growth patterns of mangrove trees from the Bragança peninsula, North Brazil. Wetl Ecol Manage 11:233-242,

Murthy KRK, Yoganarasimhan SN (1990) Flora of Coorg (Kodagu) Karnataka, India. Vimsat Publishers, Bangalore

Moore ID, Gessler PE, Nielsen GA, Petersen GA (1993) Terrain attributes: estimation methods and scale effects. In: A.J. Jakeman et al. (eds) Modeling Change in Environmental Systems. Wiley, London

Myers N, Mittermeier RA, Mittermeier CG, et al. (2000) Biodiversity hotpsots for conservation priorities. Nature 403:853-858

NASA LP DAAC (2011) ASTER Global Digital Elevation Model (GDEM). Version 2. ASTER GDEM is a product of NASA and METI. NASA EOSDIS Land Processes DAAC, USGS Earth Resources Observation and Science (EROS) Center, Sioux Falls, South Dakota (https://lpdaac.usgs.gov), accessed 20 August 2015, at http://doi.org/10.5067/ASTER/ASTGTM.002.

Nath CD, Dattaraja HS, Suresh HS et al. (2006) Patterns of tree growth in relation to environmental variability in the tropical dry deciduous forest at Mudumalai, southern India. J Biosci 31:651-669

Nath CD, Pélissier R, Ramesh BR, Garcia C (2011) Promoting native trees in shade coffee plantations of southern India: Comparison of growth rates with the exotic Grevillea robusta. Agrofor Syst 83:107-119

Nath CD, Boura A, De Franceschi D, Pélissier R (2012) Assessing the utility of direct and indirect methods for estimating tropical tree age in the Western Ghats, India. Trees 26:1017-1029

Nazma, Ganapathy PM, Bhat KM, et al. (1981) A handbook of Kerala timbers. Kerala Forest Research Institute, Peechi 
Ouédraogo D-Y, Mortier F, Gourlet-Fleury S, et al. (2013) Slow-growing species cope best with drought: evidence from long-term measurements in a tropical semi-deciduous moist forest of Central Africa. J Ecol 
1002

1003

1004

1005

1006

1007

1008

1009

1010

1011

1012

1013

1014

1015

1016

1017

1018

1019

1020

1021

1022

1023

1024

1025

1026

1027

1028

1029

1030
Schweingruber FH, Börner A, Schulze E-D (2007). Atlas of woody plant stems: evolution, structure, and environmental modifications. Springer-Verlag, Berlin

Smith WK (1978) Temperatures of Desert Plants: Another Perspective on the Adaptability of Leaf Size. Science 201:614-616

Stahle DW (1999) Useful strategies for the development of tropical tree ring chronologies. IAWA J 20:249-253

The Angiosperm Phylogeny Group (2009) An update of the Angiosperm Phylogeny Group classification for the orders and families of flowering plants: APG III. Bot J Linn Soc 161:105-121

Tomlinson PB, Longman KA (1981) Growth phenology of tropical trees in relation to cambial activity. In: Bormann FH, Berlyn G (eds) Age and growth rate of tropical trees: New dimensions for research. Yale University, New Haven, pp 7-19

Venables WN, Ripley BD (2002) Modern Applied Statistics with S, Fourth Edition. Springer, New York

Verheyden A, Kairo JG, Beeckman H, Koedam N (2004) Growth rings, growth ring formation and age determination in the mangrove, Rhizophora mucronata. Ann Bot 94:59-66

Westoby M (1998) A leaf-height-seed (LHS) plant ecology strategy scheme. Pl Soil 199:213-227

Wheeler EA, Baas P, Rodgers S (2007) Variations in dicot wood anatomy: A global analysis based on the Insidewood database. IAWA J 28:229-258

Worbes M (1989) Growth rings, increment and age of trees in inundation forests, savannas and a mountain forest in the Neotropics. IAWA Bull ns 10:109-122

Worbes M (1999) Annual growth rings, rainfall-dependent growth and long-term growth patterns of tropical trees from the Caparo Forest Reserve in Venezuela. J Ecol 87:391-403

Worbes M (2002) One hundred years of tree-ring research in the tropics - a brief history and an outlook to future challenges. Dendrochronologia 20:217-231

Worbes M, Blanchart S, Fichtler E (2013) Relations between water balance, wood traits and phenological behavior of tree species from a tropical dry forest in Costa Rica - a multifactorial study. Tree Physiol $33: 527-536$

Wright IJ, Falster DS, Pickup M, Westoby M (2006) Cross-species patterns in the coordination between leaf and stem traits, and their implications for plant hydraulics. Physiol Plant 127:445-456

Zanne AE, Lopez-Gonzalez G, Coomes DA, et al. (2009) Data from: Towards a worldwide wood economics spectrum. Dryad Digital Repository. http://datadryad.org/handle/10255/dryad.235 Accessed 6 August 2015 
1031

1032

1033

1034

1035

1036

1037

1038

1039

1040

1041

1042

1043

1044

1045

1046

1047

1048

1049

1050

1051

1052

1053

1054

1055

1056

Table 1 Basic statistics of the functional, topographic, climatic and distinctness variables used in the study

\begin{tabular}{|c|c|c|c|c|c|}
\hline Variable type & Average & Median & Standard Error & Minimum & Maximum \\
\hline \multicolumn{6}{|l|}{ Independent Variables } \\
\hline Leaf phenological type & 0.58 & 1.00 & 0.08 & 0.00 & 1.00 \\
\hline Species stature $(\mathrm{m})$ & 28.05 & 30.00 & 1.80 & 8.00 & 50.00 \\
\hline Avg. leaf length $(\mathrm{cm})$ & 12.40 & 13.41 & 0.84 & 1.06 & 23.66 \\
\hline Wood specific gravity & 0.65 & 0.65 & 0.03 & 0.40 & 1.08 \\
\hline Altitude (m) & 914.83 & 932.00 & 14.98 & 487.00 & 1048.50 \\
\hline Slope (degrees) & 10.37 & 9.74 & 0.82 & 3.41 & 30.53 \\
\hline Topographic wetness index (TWI) & 7.94 & 7.47 & 0.23 & 5.83 & 11.99 \\
\hline Dry season rainfall $(\mathrm{mm})$ & 24.99 & 24.00 & 0.36 & 19.00 & 32.00 \\
\hline Thornthwaite PET Index & 89.13 & 88.35 & 0.79 & 82.93 & 113.02 \\
\hline Hargreaves PET Index & 134.52 & 135.43 & 0.42 & 127.31 & 140.88 \\
\hline \multicolumn{6}{|l|}{ Dependent Variables } \\
\hline Visual distinctness & 0.58 & 0.50 & 0.06 & 0.00 & 1.00 \\
\hline Cumulative score & 2.88 & 2.88 & 0.28 & 0.00 & 6.75 \\
\hline Average vessel area ratio & 2.41 & 1.64 & 0.37 & 0.59 & 11.38 \\
\hline Total porosity ratio & 1.88 & 1.62 & 0.20 & 0.29 & 6.36 \\
\hline
\end{tabular}


1057

1058

1059

1060

1061

1062

1063

1064

1065

1066

1067

1068

1069

1070

1071

1072

1073

1074

1075

1076

1077

1078

1079

1080

1081

1082

1083

1084

1085

1086

1087

1088

1089

1090

1091

1092

1093

1094

1095

1096

1097

1098

1099
Table 2 Results of testing for phylogenetic signal (via phylogenetic independent contrasts, PIC) in nine independent functional and environmental variables, and in three dependent growth ring variables. The values in parentheses were the average values obtained after 1000 iterations of random selection of replicates per species ("rand.value"). The proportion of randomized iterations in which the PIC variance $p$ value was $<0.05$ is provided in the fourth column for each variable ("Prop iter. $p<0.05$ "). The ordinal variable, visual distinctness score, and the binary variable, leaf phenological type, could not be tested here

\begin{tabular}{|c|c|c|c|c|}
\hline Variable, Type & $\begin{array}{l}\text { K-statistic } \\
\text { (rand-value) }\end{array}$ & $\begin{array}{l}\text { PIC var. } p \\
\text { (rand-value) }\end{array}$ & $\begin{array}{l}\text { Prop iter. } \\
p<0.05\end{array}$ & $\begin{array}{l}\text { PIC Z-score } \\
\text { (rand-value) }\end{array}$ \\
\hline \multicolumn{5}{|l|}{ Independent Variables } \\
\hline \multicolumn{5}{|l|}{ Functional traits } \\
\hline Species stature (m) & $0.09(0.09)$ & $0.34(0.36)$ & $0 \%$ & $-0.43(-0.39)$ \\
\hline Avg. leaf length $(\mathrm{cm})$ & $0.10(0.10)$ & $0.20(0.18)$ & $0 \%$ & $-0.90(-0.92)$ \\
\hline Wood specific gravity & $0.12(0.12)$ & $0.03 *(0.03 *)$ & $100 \%$ & $-1.79(-1.79)$ \\
\hline \multicolumn{5}{|l|}{ Environmental: Topography } \\
\hline Altitude (m) & $0.08(0.08)$ & $0.49(0.53)$ & $0 \%$ & $0.14(0.11)$ \\
\hline Slope (degrees) & $0.07(0.08)$ & $0.59(0.43)$ & $1 \%$ & $0.24(-0.21)$ \\
\hline Topographic Wetness & & & & \\
\hline Index (TWI) & $0.07(0.08)$ & $0.77(0.59)$ & $0.1 \%$ & $0.83(0.29)$ \\
\hline \multicolumn{5}{|l|}{ Environmental: Climate } \\
\hline Dry season rainfall (mm) & $0.12(0.11)$ & $0.04 *(0.22)$ & $33.4 \%$ & $-1.70(-1.09)$ \\
\hline Thornthwaite PET Index & $0.08(0.08)$ & $0.52(0.57)$ & $0 \%$ & $0.30(0.28)$ \\
\hline Hargreaves PET Index & $0.11(0.10)$ & $0.06(0.22)$ & $20.6 \%$ & $-1.52(-0.98)$ \\
\hline
\end{tabular}

Dependent Variables (Growth-ring distinctness)

Subjective quantitative

Cumulative score

$0.12(0.11)$

$0.04 *(0.10)$

$30.7 \%$

$-1.58(-1.38)$

Objective quantitative

Average vessel area Ratio $0.08(0.08)$

Total Porosity ratio

$0.07(0.07)$

$0.43(0.44)$

$0 \%$

$0 \%$

$-0.12(-0.14)$

$0.81(0.76)$

$0.97(0.82)$

Statistical significance: $*=p<0.05$ 
1100

1101

1102

1103

1104

1105

1106

1107

1108

1109

1110

1111

1112

1113

1114

1115

1116

1117

1118

1119

1120

1121

1122

1123

1124

1125

1126

1127

1128

1129

Table 3 Non-parametric Spearman rank correlation estimates $(\rho)$ of four functional traits and six environmental variables, with four growth-ring distinctness variables (visual distinctness, cumulative distinctness score, vessel area ratio, and porosity ratio). $P$-values are provided in parenthesis. In the case of the dichotomous variable "Leaf phenological type", the values reported are averages of each dependent variable for evergreen and deciduous species, respectively, along with $p$-value significance (in parenthesis) according to the Mann-Whitney U test

$\begin{array}{lllll}\begin{array}{l}\text { Independent } \\ \text { variables }\end{array} & \begin{array}{l}\text { Visual } \\ \text { distinctness }\end{array} & \text { Cumulative } & \text { Vessel area } & \text { Porosity } \\ \text { score } & \text { ratio } & \text { ratio }\end{array}$

Functional traits

Leaf phenological type

$0.34,0.75$

$1.77,3.83 \quad 1.21,3.28$

$(0.00007 * * *)$

$1.38,2.25$

Species stature (m)

$(0.0005 * * *)$

$(0.0004 * * *)$

$(0.05)$

Avg. leaf length (cm)

$0.38(0.02 *)$

$0.52(0.0008 * * *)$

$0.29(0.08)$

$0.01 \quad(0.93)$

Wood specific gravity

$0.00(0.98)$

$-0.04(0.80)$

$0.00(0.98)$

$-0.05(0.78)$

Environmental variables

Altitude (m)

$-0.10(0.55)$

$-0.01(0.97)$

$-0.05(0.75)$

$-0.17(0.30)$

Slope (degrees)

TWI

$-0.01 \quad(0.95)$

$-0.12(0.48)$

$-0.25(0.13)$

$-0.13(0.45)$

$0.18(0.27)$

$0.00(0.99)$

$-0.22(0.17)$

$-0.02(0.88)$

Dry season rain (mm)

$-0.20(0.22)$

$0.22(0.18)$

$0.23(0.16)$

$-0.03(0.87)$

Thornthwaite PET Index

$0.11(0.50)$

$-0.22(0.18)$

$-0.03(0.87)$

Hargreaves PET Index

$0.19(0.26)$

$0.12(0.47)$

$0.27(0.10)$

$0.14(0.40)$

$0.10(0.57)$

$0.23(0.16)$

$0.07(0.69)$

Statistical significance: $*=p<0.05, * *=p<0.01, * * *=p<0.001$ 
Table 4 Functional traits and environmental predictor variables that were retained in parsimonious GLS models of three quantitative variables associated with distinctness of growth rings (Cumulative score, Vessel area ratio, Porosity ratio). Cell values indicate the estimated slope, $p$-value of the estimate (in parenthesis), and jackknife estimated range (minimum and maximum, within square brackets). The last row provides the jackknife support per model (percentage of iterations that returned the same final model)

\begin{tabular}{|c|c|c|c|}
\hline Predictor variables & Cumulative score $^{1}$ & Vessel area ratio ${ }^{2}$ & Porosity ratio $^{3}$ \\
\hline \multicolumn{4}{|l|}{ Functional traits } \\
\hline Leaf phenological type & $\begin{array}{l}1.69\left(0.0005^{* * *}\right) \\
{[1.42,2.12]}\end{array}$ & $\begin{array}{l}0.85\left(0.0000^{* * *}\right) \\
{[0.74,0.92]}\end{array}$ & $\begin{array}{l}0.28(0.03 *) \\
{[0.19,0.40]}\end{array}$ \\
\hline Species stature (m) & $\begin{array}{l}0.06\left(0.007^{* *}\right) \\
{[0.05,0.07]}\end{array}$ & & \\
\hline \multicolumn{4}{|l|}{ Environmental variables } \\
\hline Slope (degrees) & & $\begin{array}{l}-0.03(0.097) \\
{[-0.04,-0.02]}\end{array}$ & \\
\hline Jackknife support & $92 \%$ & $82 \%$ & $68 \%$ \\
\hline
\end{tabular}

Statistical significance: $*=p<0.05, * *=p<0.01, * * *=p<0.001$

${ }^{1}$ Altitude not included in the full model due to variance inflation

${ }^{2}$ Dependent variable was natural-log transformed; Wood specific gravity not included in the full model to increase Jackknife support for final model (without increasing AIC)

${ }^{3}$ Dependent variable was square-root transformed 


\section{Figure Captions}

Fig. 1 Map of the study area Kodagu, Western Ghats of India, showing topographic relief, 17 sampling sites and rainfall $(\mathrm{mm})$ isoclines during the driest quarter. The topographic map was downloaded from the ASTER GDEM website (https://asterweb.jpl.nasa.gov/gdem.asp) and rainfall isoclines were calculated by simple kriging using site-based dry season rainfall data downloaded from the WorldClim database (www.worldclim.org, Hijmans et al. 2005)

Fig. 2 Wood anatomy of nine tropical Indian tree species showing different levels of distinctness of growth rings, from easily recognisable distinct rings to less distinct and absent rings. In the first six images earlywood is above and latewood is below the horizontal growth ring boundary (indicated by arrows) Species shown are: a. Celtis tetrandra (Ulmaceae, distinct ring), b. Michelia champaca (Magnoliaceae, distinct), c. Gmelina arborea (Verbenaceae, distinct), d. Persea macrantha (Lauraceae, less distinct), e. Terminalia bellirica (Combretaceae, less distinct), f. Artocarpus heterophyllus (Moraceae, less distinct), g. Cinnamomum malabatrum (Lauraceae, absent), h. Artocarpus hirsutus (Moraceae, absent), i. Garcinia cambogia (Clusiaceae, absent). Scale bar at top left of each photo represents $500 \mu \mathrm{m}$

Fig. 3 Species scores plotted on the first two principal axes representing maximum variation in the data, which was obtained by ordinating four variables, representing subjective assessment of growth-ring distinctness (Visual distinctness score and Cumulative distinctness score; top left) and objective assessment of growth-ring distinctness (Vessel area ratio and Porosity ratio; bottom left). Inset panel shows eigenvalues of the four ordination axes. The scale of the graph is indicated by the grid, the size of which is given in the upper right corner (here the length of each grid square is one unit)

Fig. 4 Independent predictors and dependent variables of growth-ring distinctness plotted on the phylogeny of species ("GR" = growth ring). Data are centered, and the means are therefore 0 . Black solid circles depict positive values, white circles depict negative values. Circle size is proportional to the absolute values

Fig. 5 Evidence that suggests evolutionary lability of distinctness of growth rings across and within families of tropical angiosperm trees in the Western Ghats, India: a. Phylogenetic relationships between the 24 sampled families according to the APG III classification system, and b. Ordination of four variables associated with distinctness of growth rings, showing differences in growth-ring distinctness scores between and within 11 families, in which at least two species were sampled. The black dots represent species and the lines and ellipses represent 1.5 times the standard deviation of family scores on the axes. The scale of the graph is indicated by the grid, and the length of each grid square is one unit 
Appendix 1 Details of 38 south Indian tropical angiosperm tree species (arranged alphabetically by family) that were used for analysis of distinctness of growth rings. Plant families follow the APG III classification system and species' scientific names are based on Mabberley (2005) and the herbarium of the French Institute of Pondicherry (HIFP, http://www.ifpindia.org/content/herbarium).

1200

Family Scientific name

\section{Phenological Species stature Visual

type (m) distinctness

\begin{tabular}{|c|c|c|c|c|}
\hline Anacardiaceae & Mangifera indica $\mathrm{L}$. & $\mathrm{E}$ & 45 & 0.5 \\
\hline Apocynaceae & Tabernaemontana heyneana Wall. ${ }^{\mathrm{a}}$ & $\mathrm{D}$ & 8 & 0.5 \\
\hline \multirow[t]{2}{*}{ Bignoniaceae } & Radermachera xylocarpa K.Schum. $^{\mathrm{a}}$ & $\mathrm{D}$ & 15 & 0.5 \\
\hline & Stereospermum colais (Dillwyn) Mabb. & $\mathrm{D}$ & 30 & 0.75 \\
\hline \multirow[t]{2}{*}{ Burseraceae } & Canarium strictum Roxb. & $\mathrm{D}$ & 30 & 0.25 \\
\hline & Garuga pinnata Roxb. $^{\mathrm{a}}$ & $\mathrm{D}$ & 25 & 0.5 \\
\hline Clusiaceae & Garcinia cambogia Desr. & $\mathrm{E}$ & 12 & 0 \\
\hline \multirow[t]{2}{*}{ Combretaceae } & Terminalia bellirica (Gaertner) Roxb. & $\mathrm{D}$ & 40 & 0.5 \\
\hline & Terminalia alata Roth & $\mathrm{D}$ & 37 & 1 \\
\hline \multirow[t]{2}{*}{ Ebenaceae } & Diospyros montana Roxb. ${ }^{\mathrm{a}}$ & $\mathrm{D}$ & 15 & 0.5 \\
\hline & Diospyros sylvatica Roxb. & $\mathrm{E}$ & 35 & 0.5 \\
\hline \multirow[t]{2}{*}{ Elaeocarpaceae } & Elaeocarpus serratus L. & $\mathrm{E}$ & 18 & 0.5 \\
\hline & Elaeocarpus tuberculatus Roxb. & $\mathrm{D}$ & 40 & 0.5 \\
\hline \multirow[t]{3}{*}{ Euphorbiaceae } & Bischofia javanica Blume & $\mathrm{E}$ & 30 & 0 \\
\hline & Mallotus philippensis (Lam.) Muell.Arg. & $\mathrm{E}$ & 12 & 0.75 \\
\hline & Phyllanthus emblica L. ${ }^{\mathrm{a}}$ & $\mathrm{D}$ & 30 & 0.5 \\
\hline \multirow[t]{4}{*}{ Fabaceae } & Acrocarpus fraxinifolius Arn. & $\mathrm{D}$ & 50 & 1 \\
\hline & Albizia odoratissima (L.f.) Benth. & $\mathrm{D}$ & 25 & 0.75 \\
\hline & Dalbergia latifolia Roxb. & $\mathrm{D}$ & 40 & 1 \\
\hline & Pterocarpus marsupium Roxb. & $\mathrm{D}$ & 30 & 0.75 \\
\hline Icacinaceae & Apodytes dimidiata E.Meyer ex Arn. & $\mathrm{E}$ & 25 & 0 \\
\hline \multirow[t]{2}{*}{ Lauraceae } & Cinnamomum malabatrum J.Presl & $\mathrm{E}$ & 15 & 0 \\
\hline & Persea macrantha (Nees) Kosterm. & $\mathrm{E}$ & 33 & 0.5 \\
\hline Lythraceae & Lagerstroemia microcarpa Wight & $\mathrm{D}$ & 35 & 1 \\
\hline Magnoliaceae & Michelia champaca $\mathrm{L}$. & $\mathrm{E}$ & 36 & 1 \\
\hline Malvaceae & Grewia tiliifolia Vahl & $\mathrm{D}$ & 20 & 1 \\
\hline Meliaceae & Toona ciliata M.Roemer ${ }^{\mathrm{a}}$ & $\mathrm{D}$ & 32 & 1 \\
\hline \multirow[t]{2}{*}{ Moraceae } & Artocarpus heterophyllus Lam. & $\mathrm{E}$ & 25 & 0.25 \\
\hline & Artocarpus hirsutus Lam. & $\mathrm{E}$ & 45 & 0 \\
\hline Myristicaceae & Knema attenuata Warb. ${ }^{\mathrm{a}}$ & $\mathrm{E}$ & 20 & 0.5 \\
\hline Myrtaceae & Syzygium cumini (L.) Skeels & $\mathrm{E}$ & 35 & 0.5 \\
\hline Oleaceae & Olea dioica Roxb. & $\mathrm{E}$ & 15 & 0.5 \\
\hline Santalaceae & Santalum album L. ${ }^{\text {a }}$ & $\mathrm{E}$ & 10 & 0 \\
\hline \multirow[t]{2}{*}{ Sapindaceae } & Sapindus laurifolius Vahl & $\mathrm{D}$ & 18 & 0.5 \\
\hline & Schleichera oleosa (Lour.) Oken & $\mathrm{D}$ & 30 & 1 \\
\hline & Celtis tetrandra Roxb. $^{\mathrm{a}}$ & $\mathrm{D}$ & 30 & 1 \\
\hline \multirow[t]{2}{*}{ Verbenaceae } & Gmelina arborea Roxb. & $\mathrm{D}$ & 30 & 1 \\
\hline & Tectona grandis L.f. & $\mathrm{D}$ & 45 & 1 \\
\hline
\end{tabular}

Phenological type classification: $\mathrm{E}=$ Evergreen, $\mathrm{D}=$ Deciduous

Species stature information was obtained from the following sources: www.biotik.org; Gamble 1935;

Nazma et al. 1981; Pascal 1988; Murthy and Yoganarasimhan 1990; Rani et al 2011

1246

1247

1248

1249

1250

Visual distinctness scores were assigned per replicate as follows: $1=$ growth ring boundary visually distinct, $0.5=$ growth ring boundary less distinct, $0=$ growth ring boundary absent. Scores were averaged across replicates per species

1251 
1252 Appendix 2 Spearman non-parametric rank correlations ( $\rho$ ) between all dependent and independent variables whose values were averaged per species $(\mathrm{N}=38)$. In the case of the binary variable, leaf phenological type (first column), the entries show $p$-values obtained with the Mann-Whitney U test (or Wilcoxon test)

\begin{tabular}{|c|c|c|c|c|c|c|c|c|c|c|c|c|c|}
\hline & 1 & 2 & 3 & 4 & 5 & 6 & 7 & 8 & 9 & 10 & 11 & 12 & 13 \\
\hline 1. Leaf Phenol. & & & & & & & & & & & & & \\
\hline 2. Max height & {$[0.30]$} & & & & & & & & & & & & \\
\hline 3. Leaf Length & {$[0.10]$} & 0.16 & & & & & & & & & & & \\
\hline 4. Wood Dens. & {$[0.42]$} & -0.06 & -0.16 & & & & & & & & & & \\
\hline 5. Altitude & {$[0.24]$} & -0.20 & -0.03 & -0.01 & & & & & & & & & \\
\hline 6. Slope & {$[0.71]$} & -0.16 & -0.11 & -0.13 & $0.56^{* * * *}$ & & & & & & & & \\
\hline 7. TWI & {$[0.69]$} & 0.14 & 0.23 & 0.17 & -0.20 & -0.10 & & & & & & & \\
\hline 8. Dry seas. pptn & [0.11] & 0.06 & 0.17 & -0.06 & $0.33^{*}$ & $0.33^{*}$ & -0.08 & & & & & & \\
\hline 9. Thor. PET & {$[0.22]$} & 0.18 & 0.03 & 0.02 & $-0.99 * * *$ & $-0.55 * * *$ & 0.20 & $-0.39 *$ & & & & & \\
\hline 10. Harg. PET & {$[0.10]$} & -0.01 & -0.10 & 0.11 & $-0.46^{* *}$ & -0.28 & 0.19 & $-0.89 * * *$ & $0.53^{* * * *}$ & & & & \\
\hline 11. GR vis. dist. & {$[0.00]^{* * *}$} & $0.38^{*}$ & -0.06 & 0.00 & -0.10 & -0.01 & 0.18 & -0.20 & 0.11 & 0.19 & & & \\
\hline 12. Cumul. Score & {$[0.00]^{* * *}$} & 0.52 *** & -0.04 & -0.01 & -0.12 & 0.00 & 0.22 & -0.11 & 0.12 & 0.10 & $0.92 * * *$ & & \\
\hline 13. Ves. area ratio & {$[0.00]^{* * *}$} & 0.29 & 0.00 & -0.05 & -0.25 & -0.22 & 0.23 & -0.22 & 0.27 & 0.23 & $0.65^{* * * *}$ & 0.59 *** & \\
\hline 14. Por. ratio & {$[0.05]$} & 0.01 & -0.05 & -0.17 & -0.13 & -0.02 & -0.03 & -0.03 & 0.14 & 0.07 & $0.64 * * *$ & $0.44 *$ & $0.59^{* * *}$ \\
\hline
\end{tabular}

